\title{
Synthesis of Agglomerated Hydroxyapatite Nanospheres with Performance as Anti-Viral Material
}

\author{
E.A. Abdel-Aal ${ }^{1,{ }^{*}}$, R. Dawood ${ }^{2}$, E.M. Ewais ${ }^{1}$, W.A. Kandeel ${ }^{283}$, M.A. Shemis ${ }^{3}$, H.M. Abdel-Ghafar ${ }^{1}$ \\ ${ }^{1}$ Central Metallurgical Research and Development Institute (CMRDI), P.O. Box 87 Helwan, Cairo, Egypt \\ ${ }^{2}$ Biological Anthropology Department, Medical Division, National Research Centre, Giza, Egypt \\ ${ }^{3}$ Theodor Bilharz Research Institute, Giza, Egypt \\ *Corresponding author: E-mail: eabde2@gmail.com , Tel: (+202)7142452, Fax: (+202)7142451
}

Received: 2 April 2021

Revised: 22 May 2021

Accepted for publication: 8 June 2021

Published online: 30 June 2021

\section{Abstract}

Hydroxyapatite (HA) synthesized with the hydrothermal method was studied under various preparation conditions including variations of time, concentration of reactants, and concentration of surfactant, Aminotris (methylenephosphonic acid) $\left[\mathrm{N}\left(\mathrm{CH}_{2} \mathrm{PO}_{3} \mathrm{H}_{2}\right)_{3}\right]$ (ATMP). Well elongated crystals with high degree of crystallinity were synthesized at $150{ }^{\circ} \mathrm{C}$, initial $\mathrm{pH}$ adjusted to $9.0 \pm 0.1$ with no surfactant and a high concentration of reactants. Addition of the surfactant helped in increasing particle agglomeration and formation of clusters of micron sizes. HA crystal sizes were ranged from $1.4 \mu \mathrm{m}$ to $5.1 \mu \mathrm{m}$ whereas the crystallite sizes ranged from $26 \mathrm{~nm}$ to $38 \mathrm{~nm}$. The antiviral screening of the hydroxyapatite was performed against Viruses that represent a threat to the public health community due to their minimal symptomatic control such as HAV, HSV-1, Adenovirus and MERS. The antiviral activities of the synthesized compound were evaluated In vitro by viral infectivity Plaque assay. The obtained results revealed that the synthesized Hydroxyapatite - using $0.075 \mathrm{M} \mathrm{CaHPO}_{4}$ concentration for 25 hours hydrothermal time with 100 ppm surfactant - exhibited antiviral effect (52.9\%) against Virus HSV-1. HAV was slightly inhibited, whereas no antiviral activity was observed with respect to Adenovirus-5, and MERS.

Keywords: Hydroxyapatite; Hydrothermal synthesis; Aminotris (methylenephosphonic acid) surfactant; Experimental statistical design; Anti-Viral Plaque assay

\section{Introduction}

Many advances are being made in the particle engineering of hydroxyapatite $\left(\mathrm{Ca}_{10}\left(\mathrm{PO}_{4}\right)_{6}(\mathrm{OH})_{2}\right)(\mathrm{HA})$ with medicinal applications [1]. These include uses as bone replacement and coatings for implants that require high biocompatibility [2]. It is also useful for fraction and purification of different organic solutions [3]. It has anti-viral activities [4]. These applications require HA with specific morphology, size and mechanical properties.

The versatile nature of this compound makes it desirable in many fields of study with current emphasis being place on biomedical applications and virus purification [4]. Current routes of HA synthesis include hydrothermal and electrodeposition methods [1, 5], solid-state reaction [6], precipitation [7 - 9], sol-gel $[10,11]$, sputtering [12], mechanochemical [13, 14], mechanochemical-hydrothermal $[15,16]$, micro- emulsion [17] and others.

Poly(sodium 4-styrene-sulfonate) (PSS) was applied to accelerate HA formation with various morphologies [18]. The results show that, at definite temperature, the precipitated HA modified from fiber-like to rod-like morphology. Moreover, the morphology of HA modified from rod-like to prism-like with increasing the temperature and at certain PSS [18]. The applied initial materials are calcium nitrate and tri ammonium phosphate at initial $\mathrm{pH}$ of 10.5 [18].

Long and uniform HA whiskers with high crystallinity, controlled morphology and high aspect ratio HA whiskers were prepared using acetamide, calcium nitrate and di ammonium phosphate using precipitation method at high pressure [19]. The precipitated HA whiskers have mean lengths ranged from $60-116 \mu \mathrm{m}$ and aspect ratio ranged from 68-103. The starting solutions have concentrations ranged from 
42-84 mmol L $\mathrm{La}^{-1} \mathrm{Ca}^{2+}$ and concentrations ranged from 25-50 $\mathrm{mmol} \mathrm{L}^{-1} \mathrm{PO}_{4}^{3-}$ [19].

The surfactant, Aminotris (methylenephosphonic acid) [ATMP], was used in a study of gypsum crystallization [20]. It was found that, the crystal growth rate, the mean diameter, the formation of critical nucleus size free energy and the critical nucleus radius was decreased upon addition of this surfactant, whereas the nucleation rate was increased [20]. Similar to ATMP surfactant, citric acid and tri sodium phosphate inhibit gypsum crystallization while other surfactants assist gypsum and phosphogypsum crystallization [2126].

Large molecules such as stearic acid, monosaccharaides, and other molecules are added during HA preparation to control its morphology [27].

The main objectives of the present paper are studying the effect of Aminotris (methylenephosphonic acid) surfactant on HA morphology under the applied conditions (high temperature of $150{ }^{\circ} \mathrm{C}$ and high pressure) as well as identifying the optimum HA preparation conditions. In addition, the Anti-viral activity of the prepared HA was also assessed against four viruses by using plaque assay.

\section{Experimental}

\subsection{Hydroxyapatite synthesis}

HA was synthesized using hydrothermal method. The Box Behnken design was used to develop an experimental procedure that would identify the main effects of varying factors (Table 1). From this data, optimal conditions could be obtained and conclusions based on statistical significance could be drawn. For these experiments; time, concentration of reactants, and concentration of surfactant are varied and studied throughout 15 experiments.

The reactants used were calcium phosphate and calcium hydroxide. They were added in stoichiometric amounts. The chemical equation represents the reaction as the following:

$$
4 \mathrm{Ca}(\mathrm{OH})_{2}+6 \mathrm{CaHPO}_{4} \rightarrow \mathrm{Ca}_{10}\left(\mathrm{PO}_{4}\right)_{6}(\mathrm{OH})_{2}+6 \mathrm{H}_{2} \mathrm{O}
$$

The Box Behnken design is shown in Table 1. The desired amounts of deionized water (DI) and surfactant were added to the reactor. The surfactant used was Aminotris (methylenephosphonic acid) $\left[\mathrm{N}\left(\mathrm{CH}_{2} \mathrm{PO}_{3} \mathrm{H}_{2}\right)_{3}\right]$ from Pfaltz \& Bauer Incorporation (ATMP) $0.18 \%$ It is also called
Nitrilotrimethylphosphonic acid (Aminotris) and has the following chemical structure:

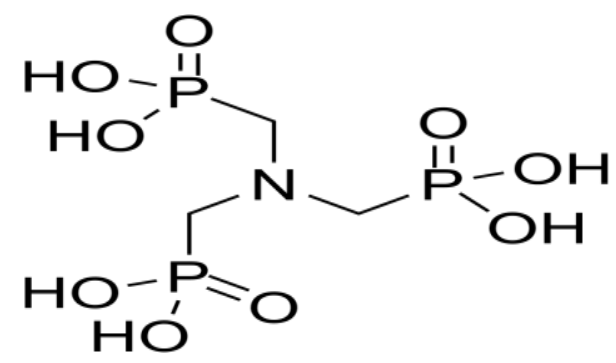

Then, the indicated amounts of calcium phosphate and calcium hydroxide were added to the solution and allowed to stir with a magnetic stir bar for one hour. The solution was then adjusted to $\mathrm{pH} 9.0 \pm 0.1$ using glacial acetic acid and ammonium hydroxide.

This buffered solution was then allowed to stir for another hour. The solution was kept under constant agitation as it was poured into the hydrothermal pressure vessel. The sample was then heated for the required time at $150{ }^{\circ} \mathrm{C}$. Afterwards, the sample was cooled to room temperature and filtered to obtain the crystallized HA. The HA solid was then washed three times with $50 \mathrm{ml}$ DI water. After filtering, the sample was dried at $60^{\circ} \mathrm{C}$ overnight.

\subsection{Hydroxyapatite characterization}

HA samples were characterized using X-ray diffraction analysis (BRUKER X-Ray Diffractometer). HA crystallite size $\left(\mathrm{L}_{\mathrm{c}}\right)$ was calculated by applying the Scherrer's equation as reported in Ref. No. 16.

HA particles were characterized using Scanning Electron Microscopy (SEM) (LEO 1455VP). Moreover, the $\mathrm{Ca} / \mathrm{P}$ ratio was determined using the energy dispersive spectrometer (EDXS, KEVEX; Germany). Also, polarized light microscope (Olympus BX60) was used to investigate the samples at magnifications of X100. Moreover, Transmission Electron Microscope (TEM, JEOL-JM1230) was used for HA particles morphology observation. In addition, Coulter Laser Diffraction Analyzer model LS230 was used for analysis of the HA particles sizes. Samples were taken from slurry of each Test. Each sample consisted of $8 \mathrm{ml}$ of slurry dispersed in $50 \mathrm{ml}$ of DI water. All samples were then sonicated for 45 minutes and kept under constant agitation immediately before analysis. Then, the sample was added into the Coulter instrument after its flushing three times with DI water. 
Table 1. The applied conditions with the achieved results of the 15 tests of experimental design.

\begin{tabular}{|c|c|c|c|c|c|}
\hline \begin{tabular}{l|l} 
Test \\
Number
\end{tabular} & $\begin{array}{l}\text { Hydrothermal } \\
\text { Time, hr }\end{array}$ & $\begin{array}{c}\text { Concentration, } \\
\mathbf{M}\end{array}$ & $\begin{array}{c}\text { Surfactant, } \\
\text { ppm }\end{array}$ & $\begin{array}{c}\text { Mean } \\
\text { Diameter, } \mu \mathrm{m}\end{array}$ & $\begin{array}{c}\text { Crystallite } \\
\text { Size, nm }\end{array}$ \\
\hline 1 & 10 & 0.025 & 50 & 2.9 & 30 \\
\hline 2 & 10 & 0.075 & 50 & 3.3 & 26 \\
\hline 3 & 40 & 0.025 & 50 & 3.1 & 36 \\
\hline 4 & 40 & 0.075 & 50 & 5.1 & 26 \\
\hline 5 & 10 & $\mathbf{0 . 0 5 0}$ & $\mathbf{0}$ & 2.0 & 33 \\
\hline 6 & 10 & $\mathbf{0 . 0 5 0}$ & 100 & 3.7 & 27 \\
\hline 7 & 40 & 0.050 & $\mathbf{0}$ & 2.5 & 34 \\
\hline 8 & 40 & 0.050 & 100 & 4.3 & 27 \\
\hline 9 & 25 & 0.025 & 0 & 1.4 & 36 \\
\hline 10 & 25 & 0.025 & 100 & 3.6 & 30 \\
\hline 11 & 25 & 0.075 & $\mathbf{0}$ & 1.7 & 38 \\
\hline 12 & 25 & 0.075 & 100 & 3.5 & 32 \\
\hline 13 & 25 & 0.050 & 50 & 3.9 & 30 \\
\hline 14 & 25 & $\mathbf{0 . 0 5 0}$ & 50 & 4.2 & 30 \\
\hline 15 & 25 & 0.050 & 50 & 4.3 & 26 \\
\hline
\end{tabular}

\subsection{Hydroxyapatite and its anti-viral activities}

The results reveal that, large agglomerated nano spheres HA are obtained with addition of the surfactant. One sample is selected to test anti-viral activity. It is worth mentioning that, the total average diameter of 11 samples with surfactant is $38.8 \mu \mathrm{m}$ and their average is $3.527 \mu \mathrm{m}$ microns which is very near to sample number 12 (3.5 $\mu \mathrm{m}$ mean diameter). So, sample number 12 is select for anti-viral activity tests.

\section{Virus and cell line}

The applied Vero cells were derived from the kidney of African green monkey. These cells were provided from the American Type Culture Collection (ATCC, Manassas, VA, USA). The cells were propagated according to procedure described in Ref. [28]. Different viruses were propagated and assayed as reported in Ref. [29]. Infectious viruses were enumerated using the Spearman-Karber method [30].

\section{MTT (4, 5-dimethylthiazol -2-yl)-2,} 5-diphenyltetrazolium bromide) assay

Mossman was reported in details a colorimetric method to calculate the $50 \%$ cytotoxicity (TC50) [31].

Cytotoxicity $\%=$ Abs. of cells with or without treatment/Abs. of cells $r$ without treatment X100

\section{Antiviral activity}

The antiviral activity was performed using Plaque inhibition assay that reported in Ref. [32].

The percentage inhibition (reduction) was calculated the following [33]:

\% Inhibition $=$ viral count $($ untreated $)-$ viral count (treated)/viral count (untreated) x 100

\section{Results and Discussion}

\subsection{Fifteen tests of experimental design results}

The obtained results of the 15 tests of the experimental statistical Box-Behnken design with their experimental conditions are given in Table (1). The Box-Behnken statistical design program was applied to the obtained results. Effect of Aminotris (methylenephosphonic acid) surfactant on hydrothermal synthesis of hydroxyapatite was studied for the first time to the best of our knowledge. If we compare between the XRD and the morphologies of the crystalized hydroxyapatite crystals of tests numbers $5 \& 6,7 \& 8,9 \& 10,11 \& 12$ - (first number without surfactant and the other number with surfactant, other conditions are similar for each pair)- the XRD peaks intensities and crystallite sizes are much higher with surfactant. On the contrary, the mean diameters of the cited crystals are much lower with surfactant. The resulting graphs are presented and discussed in details 
below showing general trends illustrating the most significant factors affecting the mean diameter of the precipitated hydroxyapatite (HA) particle sizes.

\subsection{Effect of hydrothermal time and reactants concentrations on HA mean diameter}

Fig. 1 shows the effects of hydrothermal time and concentration of reactants using different surfactant concentrations $(0,50 \mathrm{ppm}$ and $100 \mathrm{ppm})$ on mean diameter of precipitated HA. From these results it can be seen that, with increasing the hydrothermal reaction time and reactants concentration, the HA particle size was increased at all levels of surfactant concentrations. The largest particles were obtained from a high concentration $\left(0.075 \mathrm{M} \mathrm{CaHPO}_{4}\right)$ for the longest hydrothermal reaction time (40 hours). The smallest particles are obtained with a low concentration and a short hydrothermal time.

\subsection{Effect of surfactant and reactants concentrations on HA mean diameter}

Fig. 2 illustrates the effects of surfactant and reactants concentrations for different hydrothermal reaction times ( $10 \mathrm{hr}, 25 \mathrm{hr}$ and $40 \mathrm{hr}$ ) on precipitated HA mean diameter. Larger particles were obtained from higher concentration of surfactant (100 ppm) and the highest reactant concentration $(0.075 \mathrm{M})$ at all applied hydrothermal reaction times. The smallest particles were obtained with a low concentration $(0.025$ $\mathrm{M} \mathrm{CaHPO}_{4}$ ) and without addition of surfactant.

\subsection{Effect of hydrothermal time and surfactant concentration on HA mean diameter}

Fig. 3 illustrates the effects of hydrothermal reaction time and surfactant concentrations using different reactant concentrations $(0.025 \mathrm{M}, 0.05 \mathrm{M}$ and $0.075 \mathrm{M})$ on mean diameter of precipitated HA. The largest particles were obtained at high concentration of surfactant (100 ppm), high reactant concentration (075 $\mathrm{M} \mathrm{CaHPO}_{4}$ ) for long hydrothermal reaction time (40 hours). The smallest particles were obtained with a short hydrothermal time (10 hours), and low concentration of reactant without surfactant.

\subsection{Effect of hydrothermal time, surfactant concentration and reactant concentration on HA mean diameter}

From these results, it can be concluded that, the reaction time, reactant concentration as well as surfactant concentration are effective parameters on rapid crystallization of high mean diameter of HA powders. All the experimental data are collected at the 3-D cube and is given in Fig. 4. This cubic diagram shows that mean diameter of 4.52 microns could be achieved at high levels of all the parameters (hydrothermal time, surfactant and reactant concentrations). On the other hand, the smallest mean diameter (1.22 microns) can be obtained at low levels of all the parameters. Decreasing any of the parameters led to a decrease of HA mean diameter.

\subsection{Characterization of precipitated powders}

The precipitated powder was characterized using XRD, SEM, EDX and Laser Size Distribution. X-ray diffraction patterns (Fig. 5) was conducted on the 15 samples. The crystallized phase was confirmed as hydroxyapatite [JCPDS \# 00-009-0432]. Less intense peaks were observed with the samples 5, 9, and 11 .

These samples prepared without surfactant. So, surfactant may be help to obtain well crystallized crystals. Sample No. 7 is relatively well crystalized (high intense peaks) despite it has no surfactant. This is attributed to long crystallization time of HA (40 hr). The determined crystallites sizes were ranged from 26 to $38 \mathrm{~nm}$ as shown in Table (1).

Optical microscopic photomicrographs of the crystallized HA powder samples are given in Fig. 6. These HA crystals are synthesized from various conditions. Tests 5, 9 and 11 gave rods of micron sizes. Test 7 gave clusters with short rods. All these samples are prepared without addition of Aminotris (methylenephosphonic acid) as surfactant. On the other hand, the other tests gave agglomerated spheres.

Fig. 7 shows SEM images of the crystallized HA powder samples (tests 5, 6, 11 and 12). It is clear that, the crystallized HA powders from tests 5 and 11 have rod-like shape. Tests 6 and 12 gave agglomerated nano spheres.

Fig. 8 shows EDX Analysis of the crystallized HA. $\mathrm{Ca} / \mathrm{P}$ ratio was 1.67 which is typical for HA.

Fig. 9 shows TEM image of the crystallized HA powder samples (test 12). It is clear that, the crystallized HA powders from test 12 have $30-70 \mathrm{~nm}$ size spherical shape particles. These particles are agglomerated to nanospheres with further agglomeration to micron spheres as shown from SEM.

Fig. 10 shows the particle size distribution of 5 samples (test 1 to 5 ). The mean diameter of the samples was ranged from $2.0 \mu \mathrm{m}$ to $5.1 \mu \mathrm{m}$ (Table 1). 


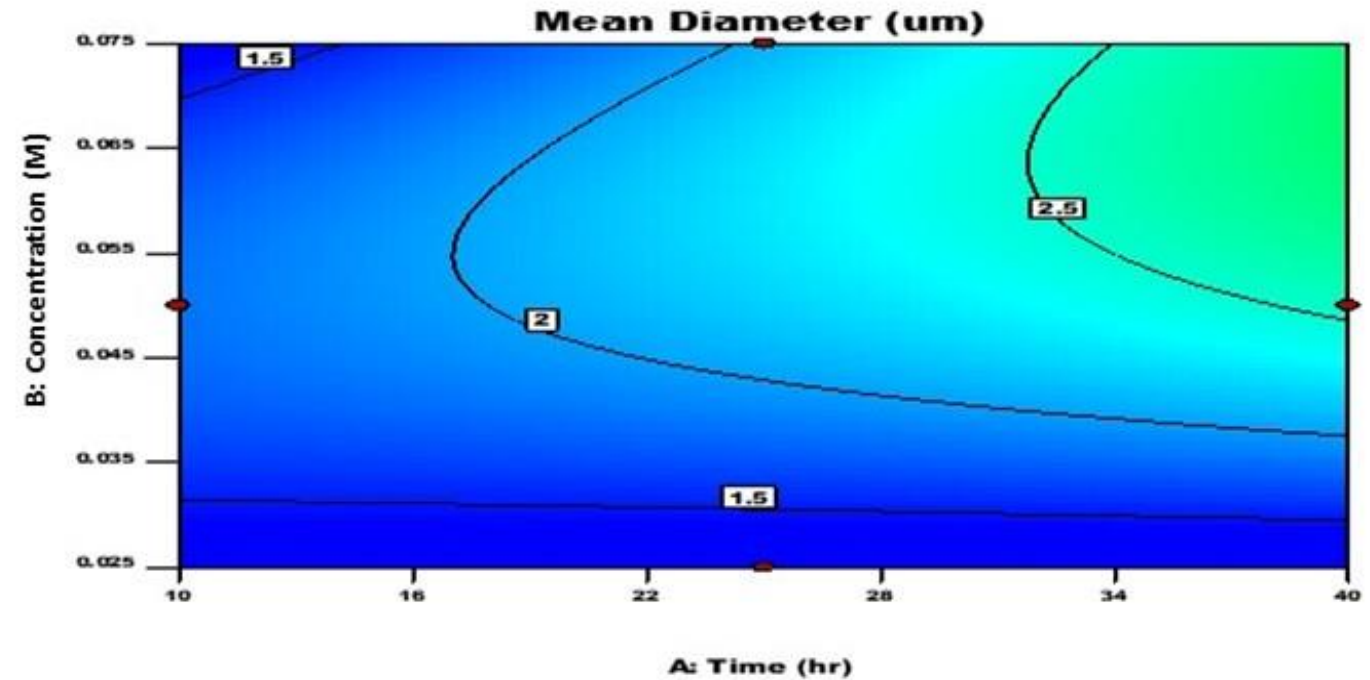

Without Surfactant

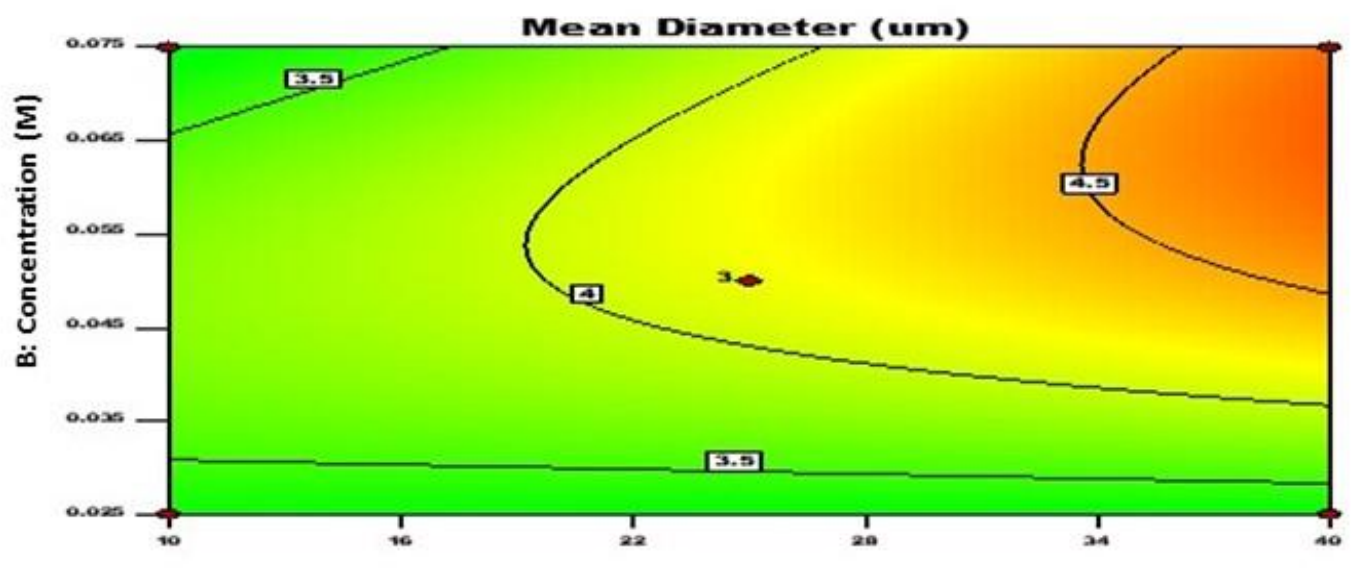

Ar Timo (hr)

With 50 ppm Surfactant

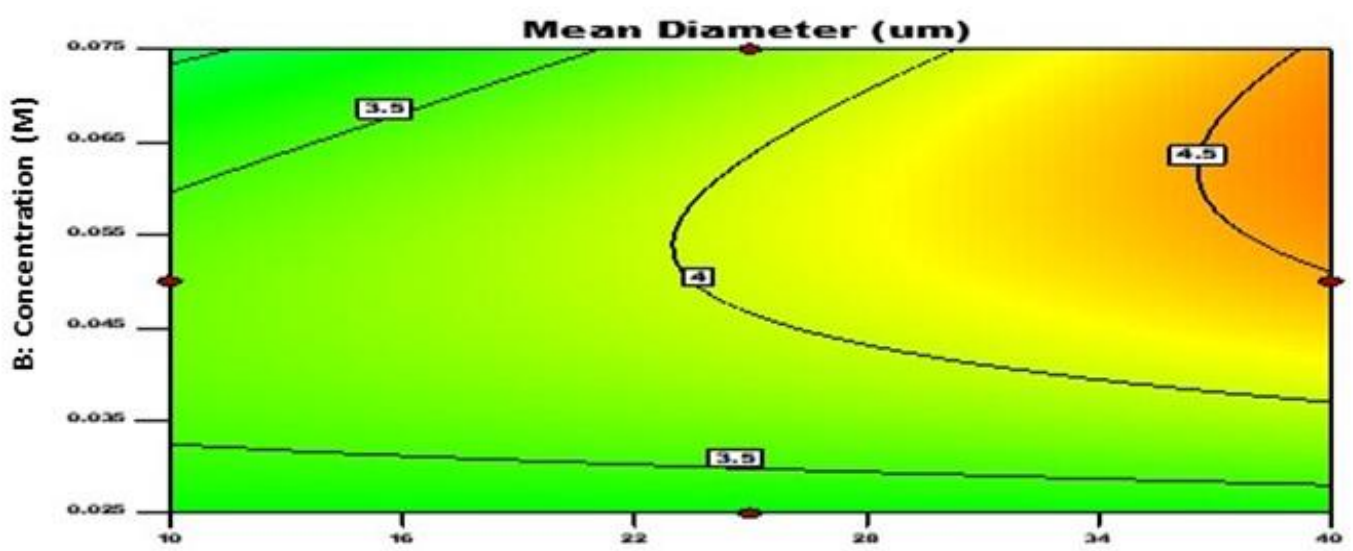

With 100 ppm Surfactant

A: Time (hn

Fig. 1 Effect of hydrothermal time and reactants concentration on HA mean diameter (at different surfactant concentration). 

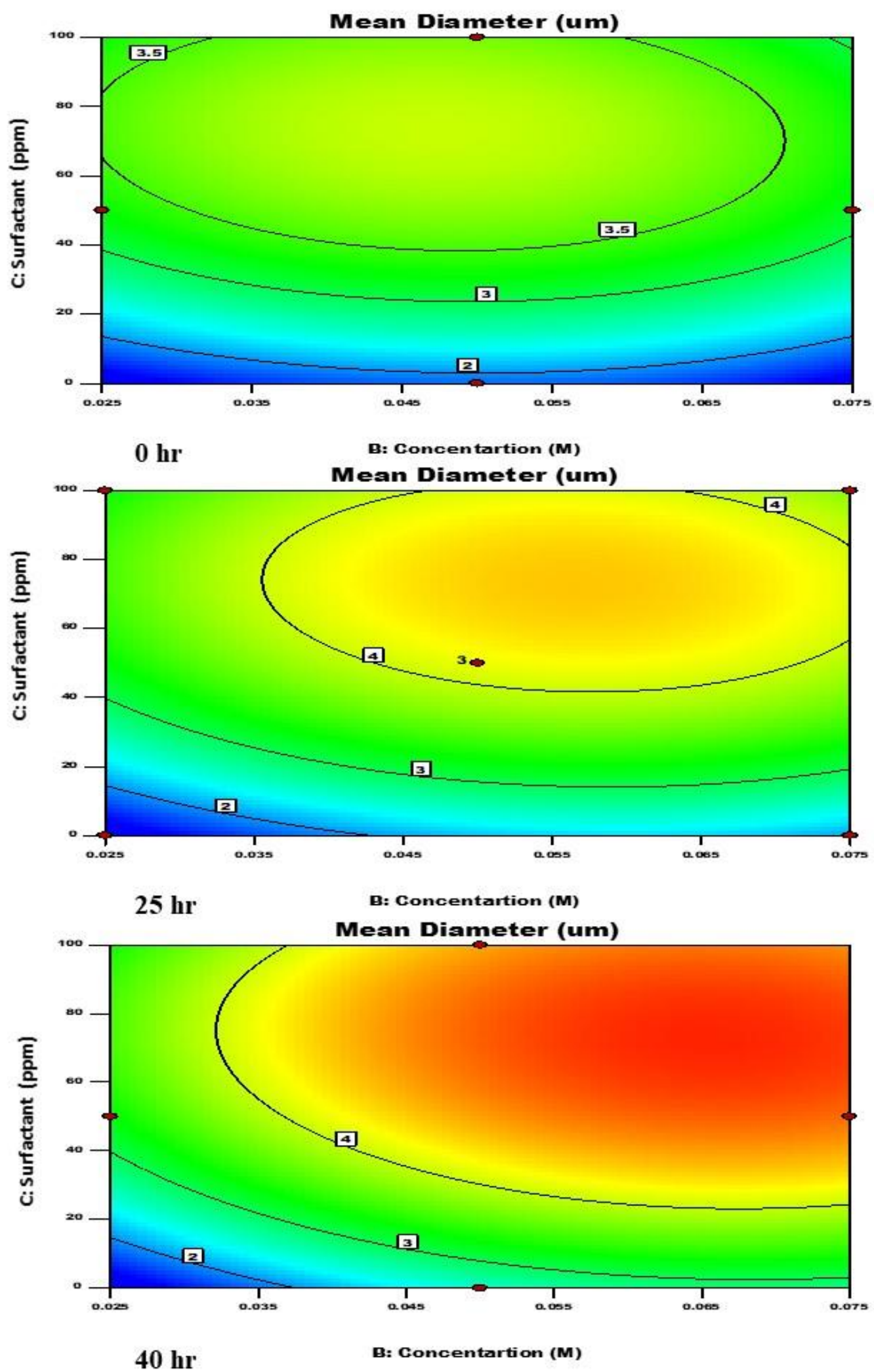

Fig. 2 Effect of surfactant and reactants concentrations on HA mean diameter (at different hydrothermal times). 

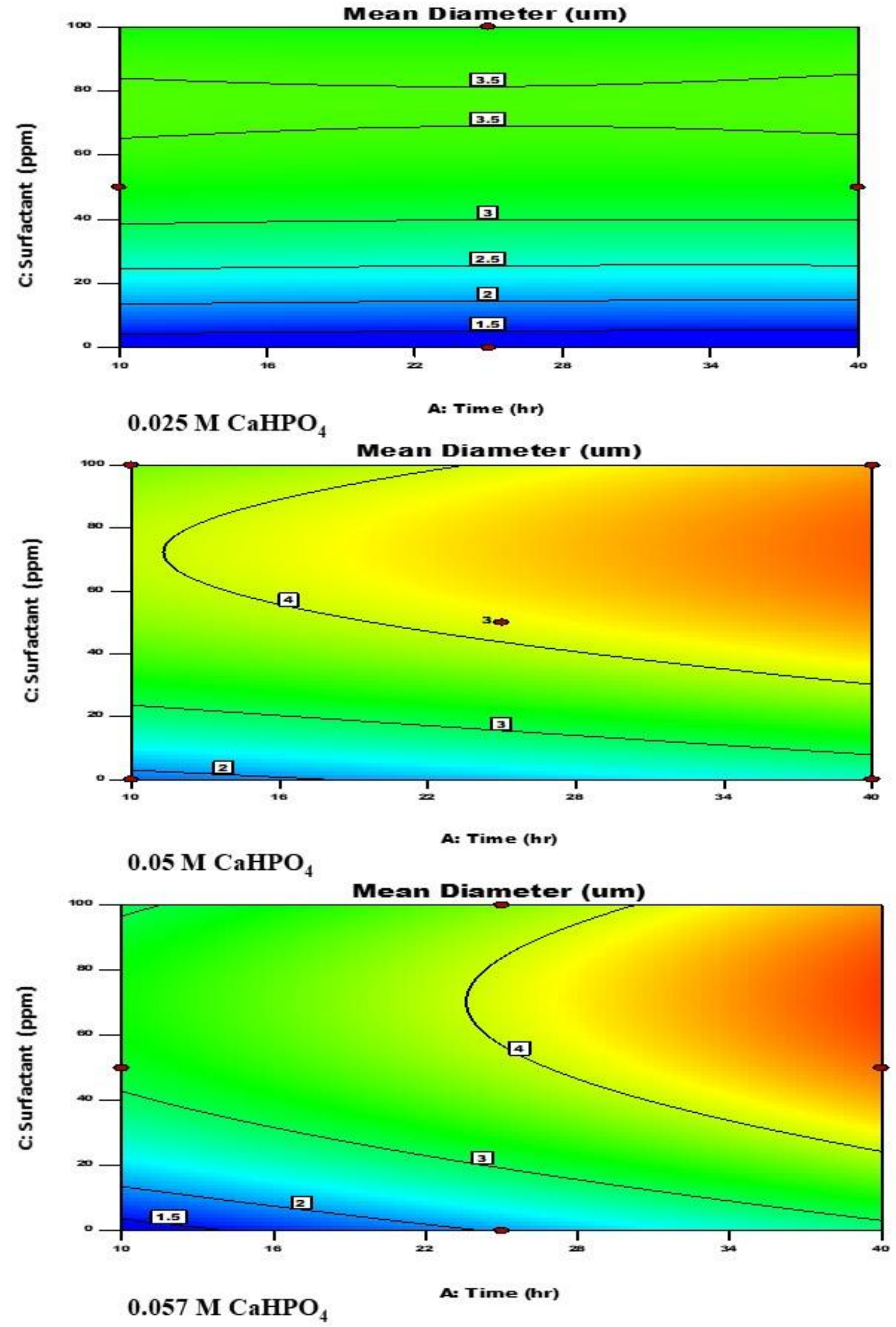

Fig. 3 Effect of hydrothermal time and surfactant concentration on HA mean diameter (at different reactant concentration). 


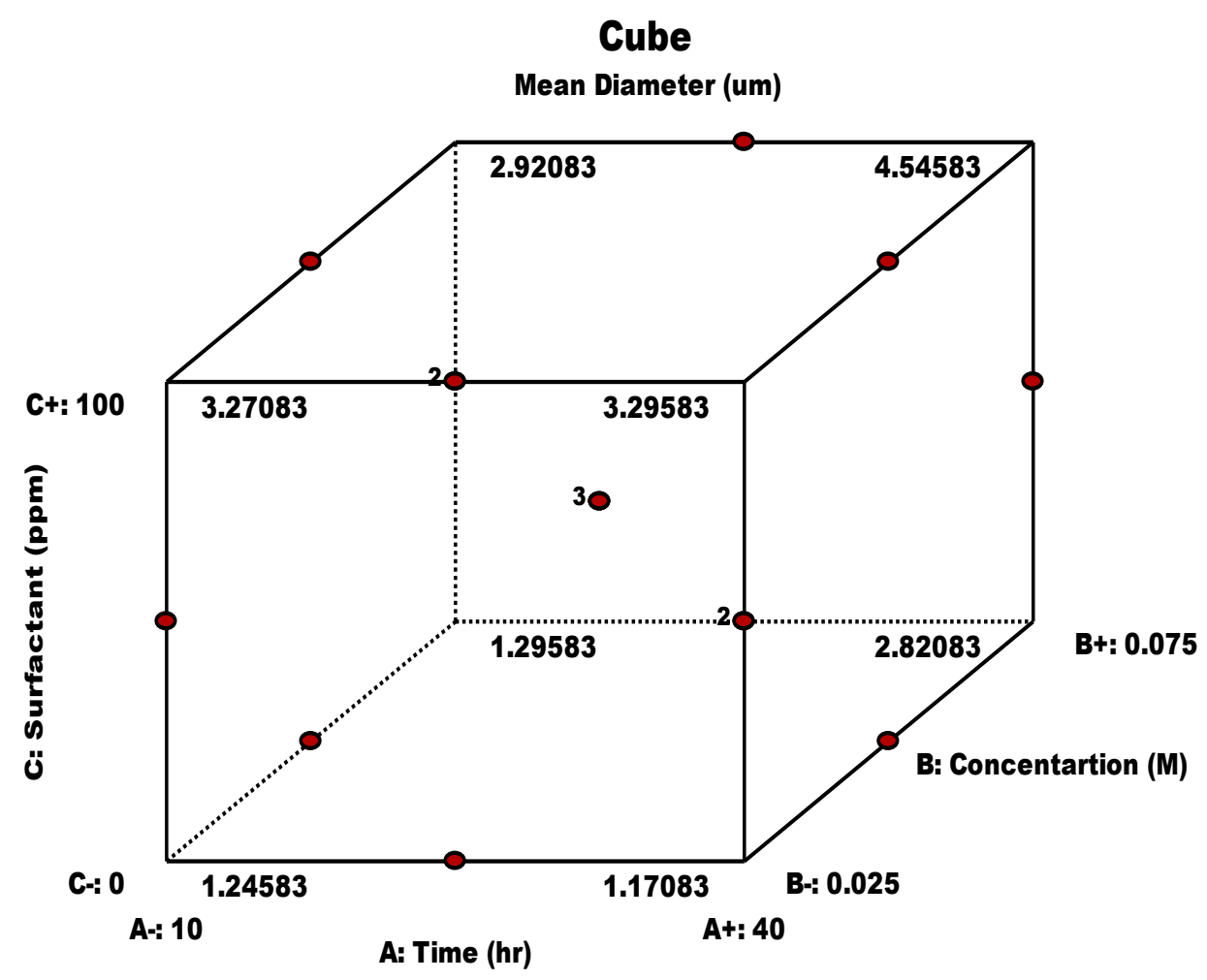

Fig. 4 3-D Plot for the Experimental Data.

\subsection{Mechanism of hydroxyapatite precipitation and its morphology modification}

Precipitation of HA is a very rapid crystallization process which involves high supersaturation stage, instantaneous nucleation stage followed by crystal growth stage [20]. A solution containing ordered aggregates of molecules of various sizes is principal to high supersaturation. The nucleus will grow in size after an aggregate exceeds the critical nucleus size [34]. So, high supersaturation is mandatory parameter for any crystallization process as it initiates and propagates nucleation of the crystals. The $\mathrm{pH}$ of solution was adjusted to $9 \pm 0.1$. However, localized $\mathrm{pH}$ on the surface of solids can goes up to about 12 .

Fig. 11 shows the distribution of phosphate species at hydrothermal temperature used $\left(150^{\circ} \mathrm{C}\right)$. Our data was processed using the computer program PHREEQC. It is clear that at $\mathrm{pH}$ 9, the predominant phosphate species is $\mathrm{HPO}_{4}{ }^{2-}$ while $\mathrm{PO}_{4}{ }^{3-}$ ions start to increase from $\mathrm{pH} 10$. Moreover, $50 \% \mathrm{HPO}_{4}{ }^{2-}$ ions with $50 \% \mathrm{PO}_{4}{ }^{3-}$ ions distribution is occurred at $\mathrm{pH}=12.163$.
Regarding the chemicals used here, the solubility of calcium hydrogen phosphate (Dicalcium phosphate) is $0.02 \mathrm{~g} / 100 \mathrm{ml}$ water and the calcium hydroxide solubility is $0.173 \mathrm{~g} / 100 \mathrm{ml}$ water at $20^{\circ} \mathrm{C}$. The chemicals and water are mixed followed by adjusting the $\mathrm{pH}$ to $9 \pm 0.1$. The concentrations used here is very high to obtain solutions. During hydrothermal process and for prolonged time, the reactants are gradually and continuously dissolve in the medium. The proposed chemical reaction is as follow:

$6 \mathrm{CaHPO}_{4}+3 \mathrm{Ca}(\mathrm{OH})_{2} \rightarrow 3 \mathrm{Ca}_{3}\left(\mathrm{PO}_{4}\right)_{2}+6 \mathrm{H}_{2} \mathrm{O}$

It was proven that, alkali treatment at high temperature converts brushite and/or tricalcium phosphate to hydroxyapatite [35-37]:

$3 \mathrm{Ca}_{3}\left(\mathrm{PO}_{4}\right)_{2}+\mathrm{Ca}(\mathrm{OH})_{2} \rightarrow \mathrm{Ca}_{10}\left(\mathrm{PO}_{4}\right)_{6}(\mathrm{OH})_{2}$

Summation of Equation (2) and Equation (3), we can obtain Equation (1) that already reported under Experimental. 


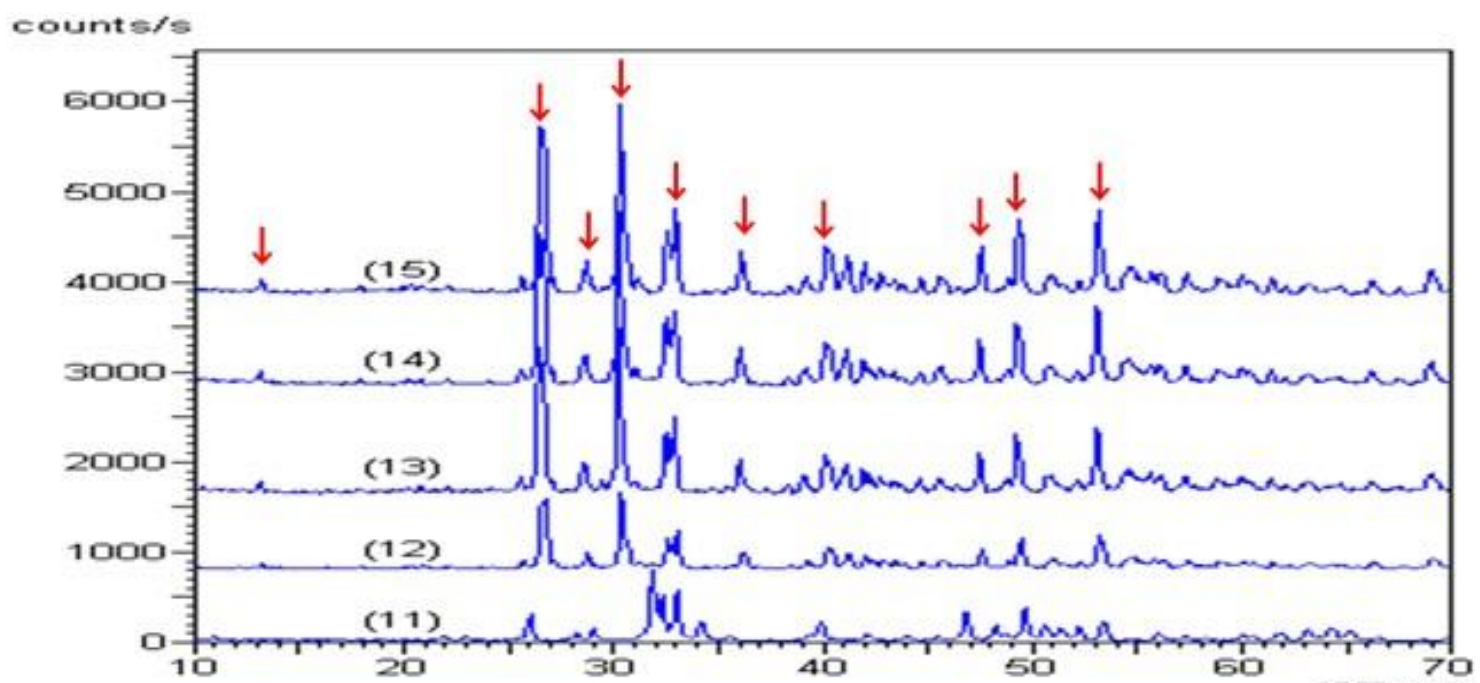

counts/s
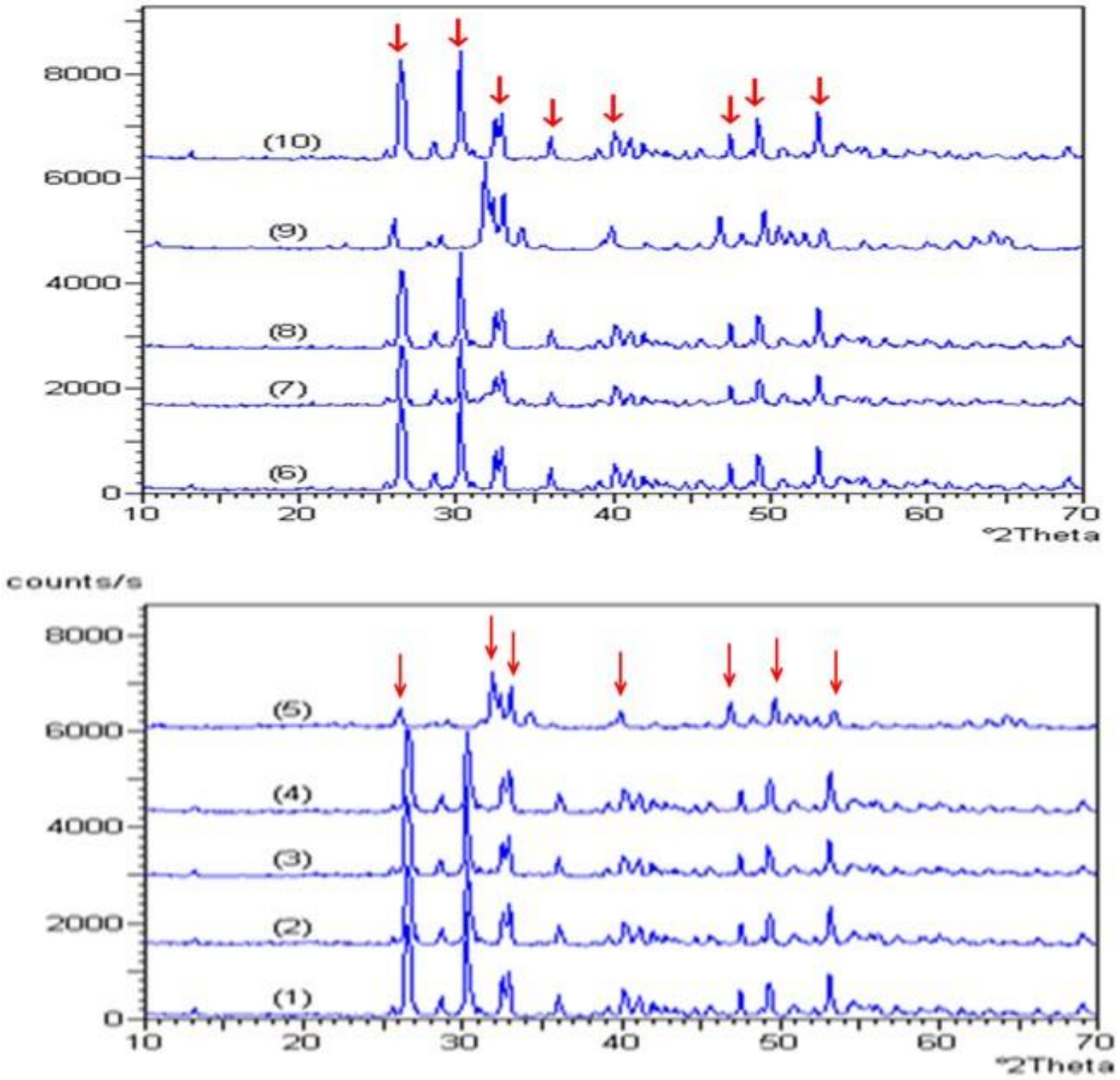

Fig. 5 XRD Pattern of Crystallized Hydroxyapatite Powder (15 Samples HA $\downarrow$ ). 


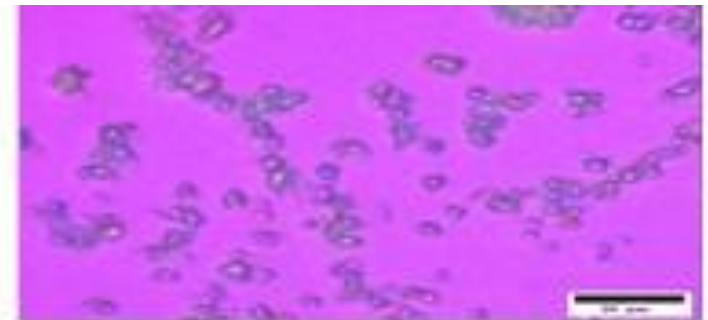

Test 1

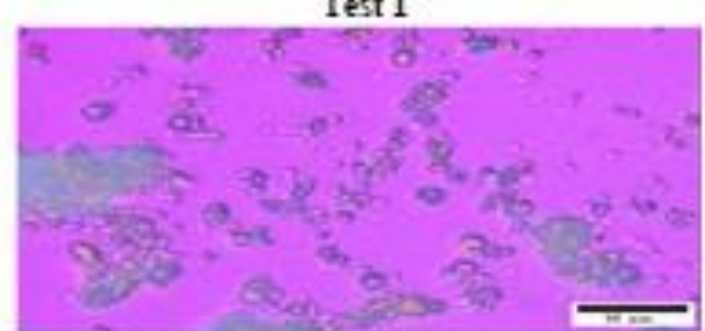

Test 3

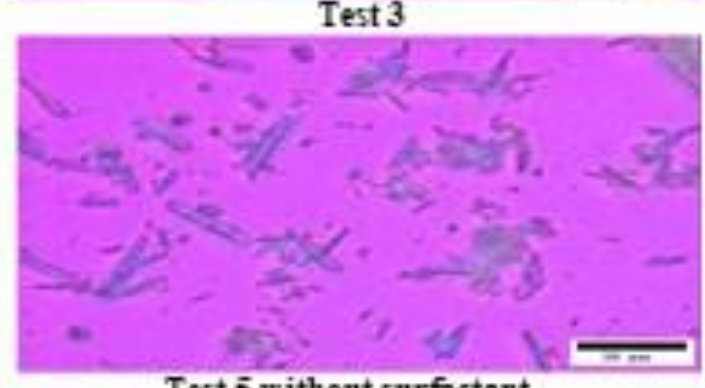

Test $\overline{5}$ without surfinctant

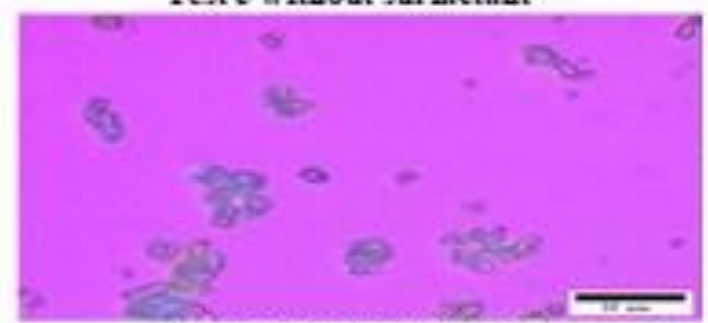

Test 7 without surfinctant

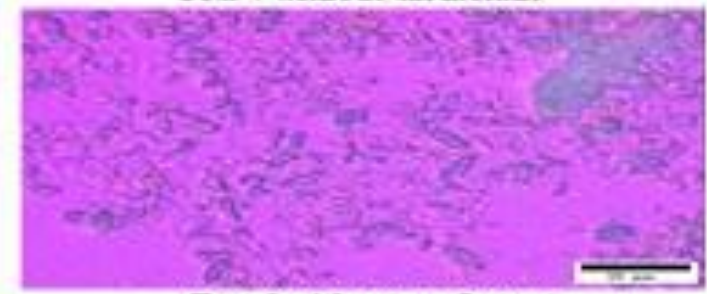

Test 9 without surfact ant

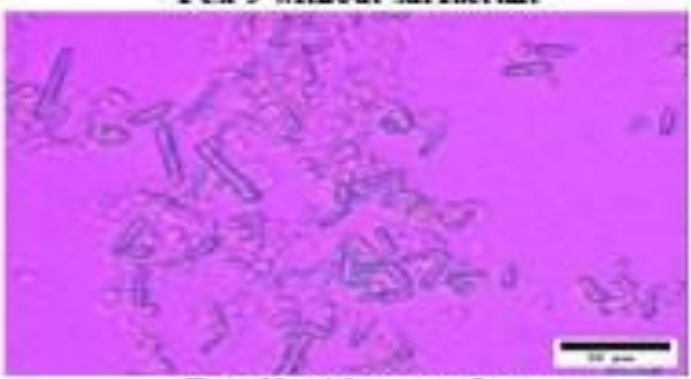

Test 11 withont surfactant

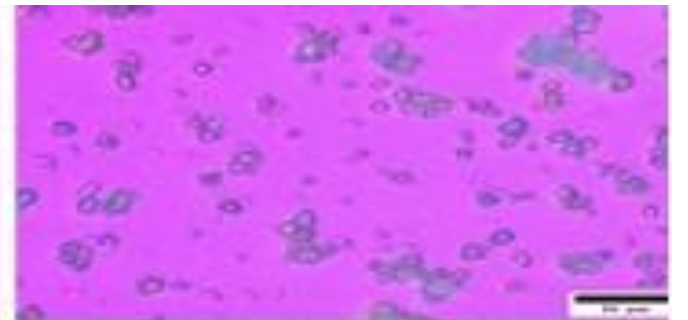

Test 2

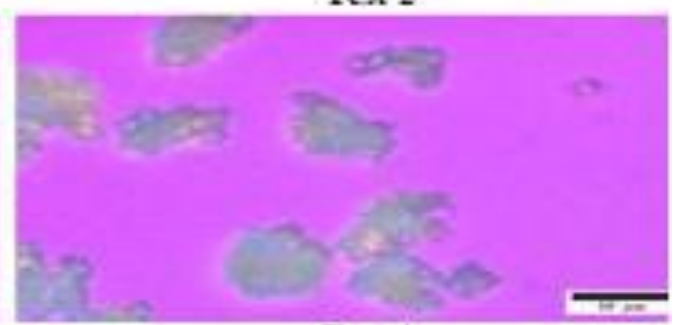

Test 4

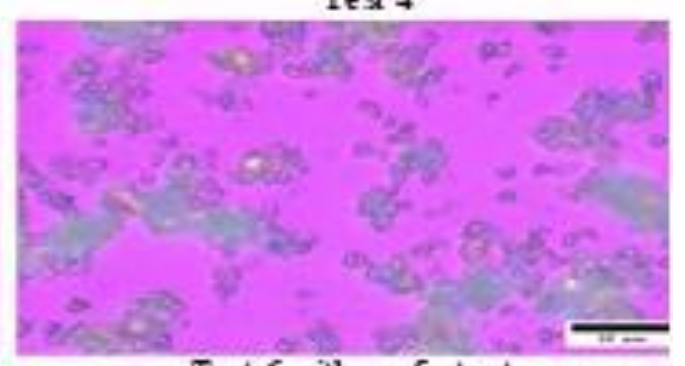

Test 6 with surfinctint

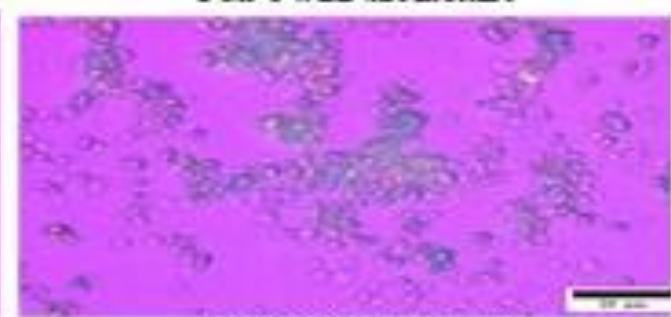

Test 8 with surfinctant

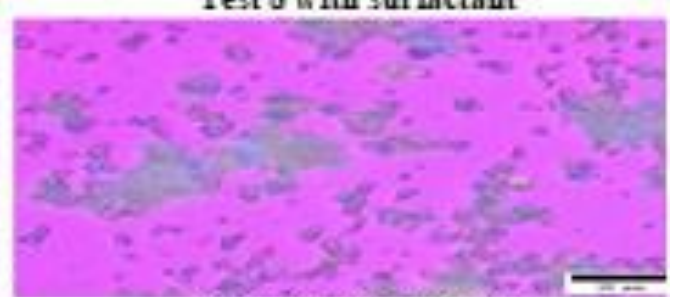

Test 10 with surfictant

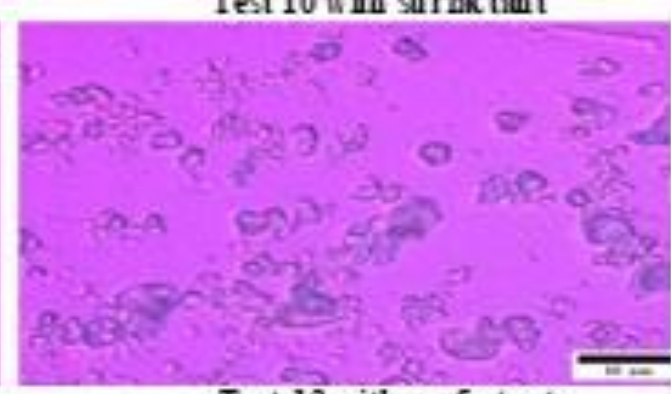

Test 12 with surfact ant

Fig. 6 Optical photomicrograph of crystallized hydroxyapatite powder samples. 


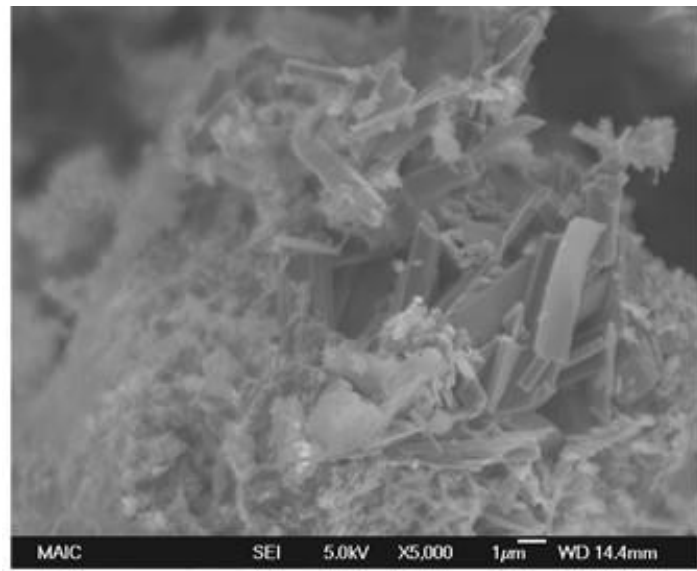

Test $\mathbf{5}$ without surfactant

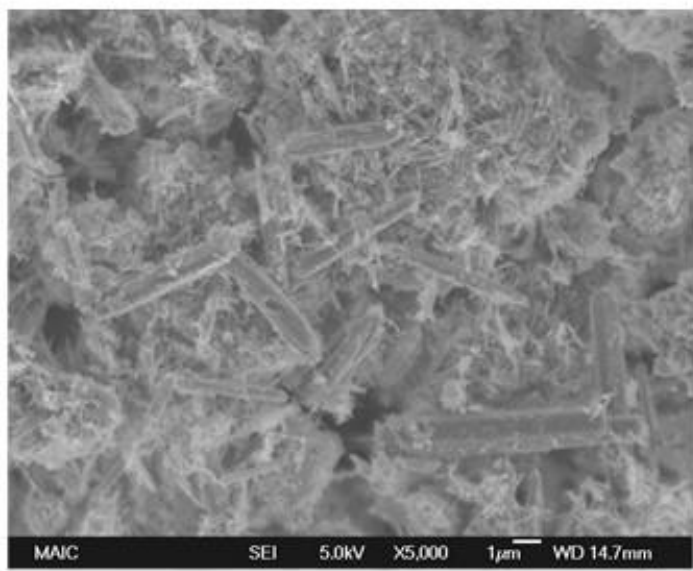

Test 11 without surfactant

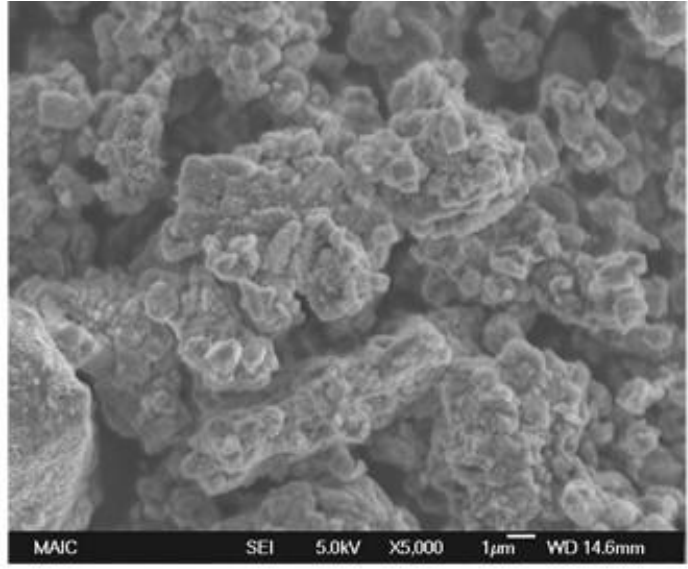

Test 6 with surfactant

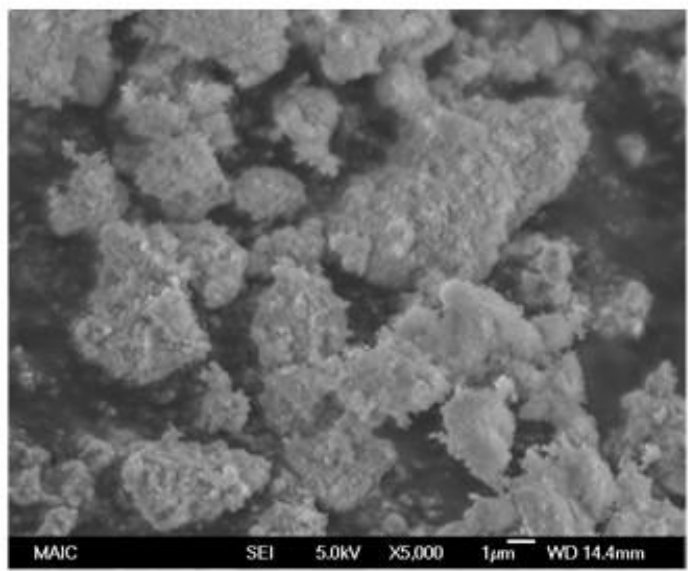

Test 12 with surfactant

Fig. 7 SEM photomicrograph of crystallized hydroxyapatite powder.

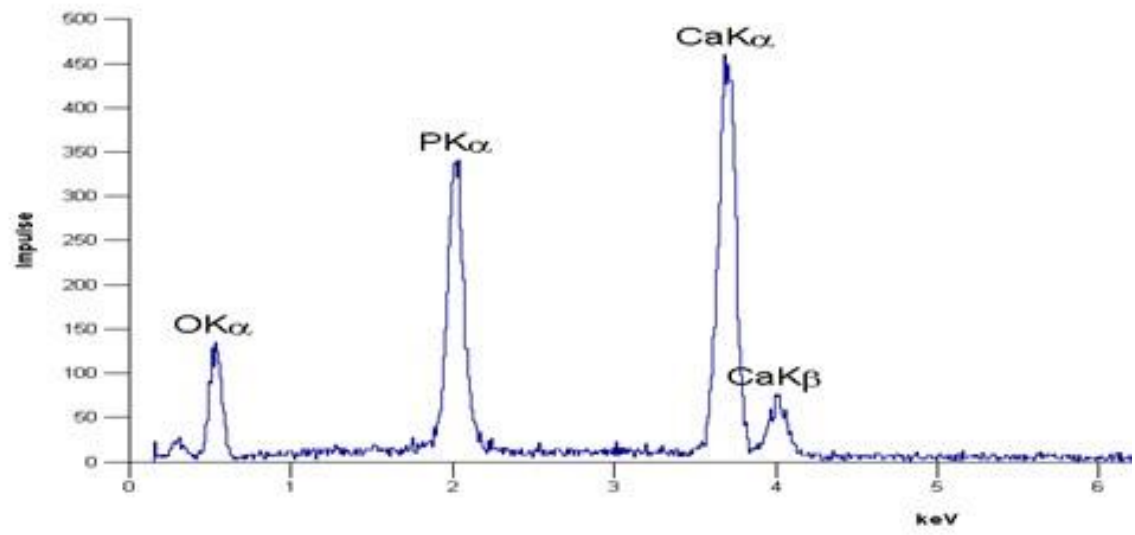

Fig. 8 EDX of crystallized hydroxyapatite powder. 


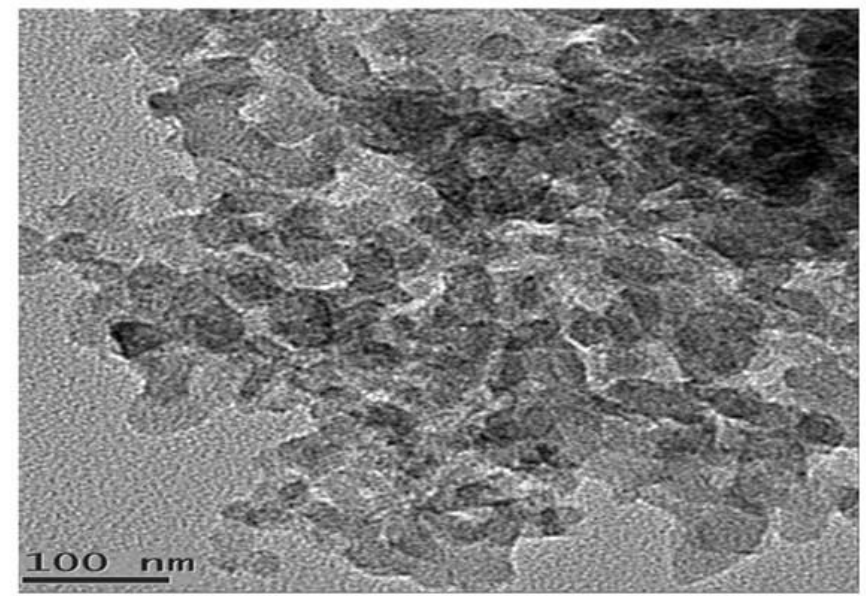

Fig. 9 TEM of crystallized hydroxyapatite powder (Test 12).

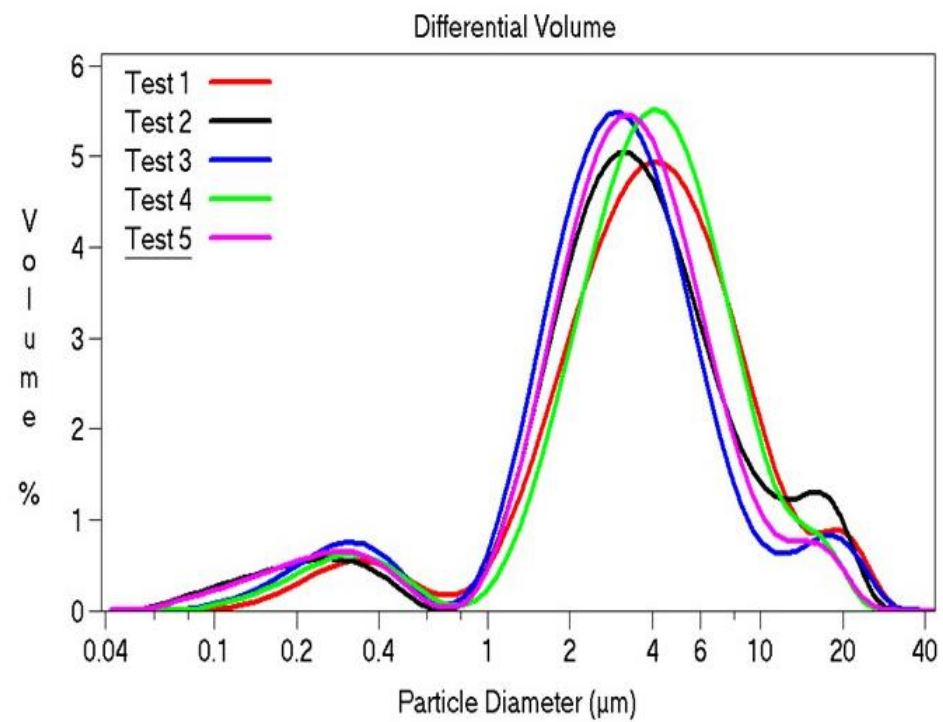

Fig. 10 Particle size distribution of hydroxyapatite powder (Test 15).

Effect of Aminotris (methylenephosphonic acid) [ATMP] additive on HA crystal modification is attributed to sequestering (chelating of calcium ions) which lead to decreasing the supersaturation ratio as well as decreasing the crystal growth rate. In presence of this surfactant, the agglomeration process will be the most predominant process rather than formation new nuclei.

ATMP is a water-soluble surfactant $(61 \mathrm{~g} / 100 \mathrm{ml})$. In solution, it partially hydrolyzed to anions with hydrophilic group (phosphonic groups and their counter ions). The anionic phosphonic groups have high tendency to attract the cationic ions (+ve charge). The influences of ATMP on HA crystals nucleation, growth and agglomeration could be attributed to:
* The -ve phosphonic groups can decrease the supersaturation by chelating to the $\mathrm{Ca}^{2+}$ cations, and then enhancing the regular crystal growth and agglomeration rather than increasing small nuclei formation rate. So, ATMP prevents scale formation in water systems.

* The -ve phosphonic groups can attract onto HA (+ve charge faces) HA has two different types of sites as in the following:

* P sites occur on the $(\mathrm{a}, \mathrm{b})$ crystal faces which are deficient in $\mathrm{Ca}^{2+}$ ions.

* C sites occur on the $(\mathrm{a}, \mathrm{c})$ or $(\mathrm{b}, \mathrm{c})$ crystal faces, namely, $\{100\}$ and $\{010\}$ facets of the nuclei which are rich in $\mathrm{Ca}^{2+}$ ions $[18,38]$ and finally leading to HA crystals modification. 


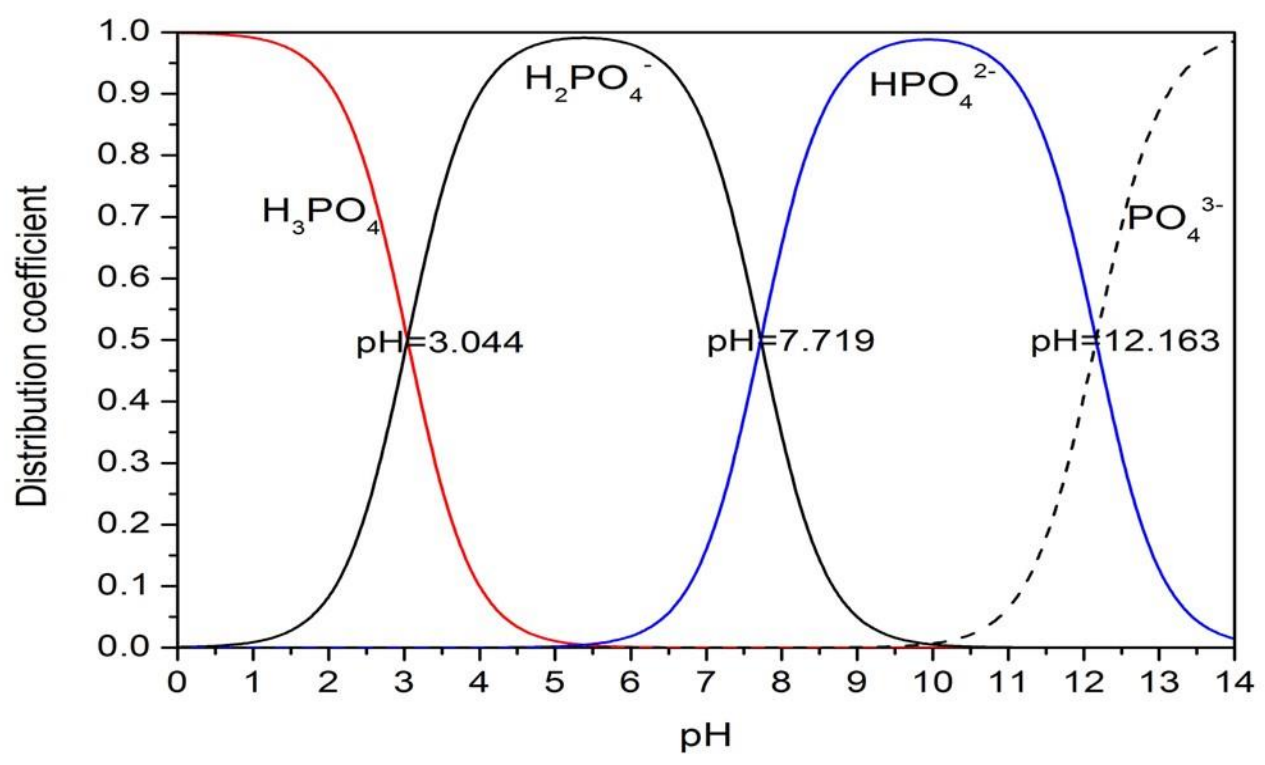

Fig. 11 The distribution of phosphate species as a function of $\mathrm{pH}$ at $150{ }^{\circ} \mathrm{C}$.

It is worth mentioning that, ATMP surfactant reduces the HA crystals interfacial tension and consequently preventing surface agglomeration.

HA crystals grow in the presence of enough free $\mathrm{Ca}^{2+}$ ions in the solution with and without ATMP. This means crystallization at high supersaturation ratio, so more nuclei are generated with low crystal growth.

Chelating assisted hydrothermal synthesis of HA has been successful in formation of HA agglomerated nanospheres. ATMP surfactant poses the ability to regulate the HA nucleation as well as HA crystal growth.

\subsection{Determination of samples cytotoxicity on Vero cell}

The cytotoxicity on Vero cell samples are given in the Table (2). These results reveal that, no cytopathic effect for this sample on Vero cells at the given concentration.

\section{Antiviral activity}

Hydroxyapatite sample No. 12 had been applied for testing its antiviral activities against Viruses HAV, HSV-1 Adenovirus and MERS. The antiviral effects of the tested HA sample on the three viruses as tested at maximum noncytotoxic concentration (MNCC) are given in Table (3). The obtained results revealed that the synthesized HA - using $0.075 \mathrm{M} \mathrm{CaHPO}_{4}$ concentration for 25 hours hydrothermal time with 100 ppm surfactant - exhibited antiviral effect (52.9 $\%)$ against Virus HSV-1. HAV was slightly inhibited, whereas no antiviral activity was observed with respect to Adenovirus-5, and MERS.

\section{Conclusions}

Based on the results of the 15 hydrothermal treatment tests, it appears that the addition of Aminotris (methylenephosphonic acid) $\left[\mathrm{N}\left(\mathrm{CH}_{2} \mathrm{PO}_{3} \mathrm{H}_{2}\right)_{3}\right]$ (ATMP) surfactant helps for formation of agglomerated hydroxyapatite (HA). Synthesis in the absence of surfactant resulted in formation of HA of needle-type or small rods or tabular crystals. Statistical experimental design analysis indicates that increasing the concentration of surfactant, concentration of reactants, and hydrothermal time led to formation of large agglomerated HA particles. The HA particles are formed from agglomerated nanospheres HA. Nanospheres HA were formed at relatively low supersaturation as a result of chelation of surfactant with calcium ions. The crystallite sizes of HA are ranged from $26 \mathrm{~nm}$ to $38 \mathrm{~nm}$. The antiviral screening of the HA was performed against Viruses that represent a threat to the public health community due to their minimal symptomatic control such as HAV, HSV-1, Adenovirus and MERS. The antiviral activities of the synthesized compound were evaluated In vitro by viral infectivity Plaque assay. 
Table 2. Cytotoxicity on Vero cell samples

\begin{tabular}{|c|c|c|c|c|c|c|c|c|}
\hline \multicolumn{1}{|c|}{ ID } & $\boldsymbol{\mu g} / \mathbf{m l}$ & \multicolumn{3}{|c|}{ O.D. } & Mean O.D & $\begin{array}{c}\text { Viability } \\
\%\end{array}$ & $\begin{array}{c}\text { Toxicity } \\
\%\end{array}$ & $\begin{array}{c}\text { SEM } \\
\pm\end{array}$ \\
\hline Vero & --- & 0.356 & 0.371 & 0.344 & 0.357 & 100 & 0 & 0.00781 \\
\hline \multirow{5}{*}{ Sample 1 } & 3000 & 0.341 & 0.359 & 0.362 & 0.354 & 99.15966 & 0.840336 & 0.006557 \\
\cline { 2 - 9 } & 1500 & 0.353 & 0.355 & 0.361 & 0.356333 & 99.81326 & 0.186741 & 0.002404 \\
\cline { 2 - 10 } & 750 & 0.362 & 0.357 & 0.352 & 0.357 & 100 & 0 & 0.002887 \\
\cline { 2 - 9 } & 375 & 0.355 & 0.359 & 0.357 & 0.357 & 100 & 0 & 0.001155 \\
\cline { 2 - 9 } & 187.5 & 0.353 & 0.362 & 0.354 & 0.356333 & 99.81326 & 0.186741 & 0.002848 \\
\cline { 2 - 9 } & 93.75 & 0.358 & 0.352 & 0.361 & 0.357 & 100 & 0 & 0.002646 \\
\hline
\end{tabular}

Table 3. Antiviral effects against the three viruses

\begin{tabular}{|l|c|c|c|c|}
\hline Virus Name & $\begin{array}{c}\text { MNCC, } \\
\boldsymbol{\mu g} / \mathbf{m l}\end{array}$ & $\begin{array}{c}\text { Virus control } \\
(\text { PFU/ml) }\end{array}$ & $\begin{array}{c}\text { Viral count } \\
(\text { PFU/ml) }\end{array}$ & Antiviral Effect, \% \\
\hline HAV-10 & 1500 & 52 & 43 & 17.3 \\
\hline HSV-1 & 1500 & 92 & 43.33333 & 52.9 \\
\hline Adeno & 1500 & 36 & 47 & 0 \\
\hline MERS & 1500 & $33 \times 10^{-3}$ & $35 \times 10^{-3}$ & 0 \\
\hline
\end{tabular}

The obtained results revealed that the synthesized $\mathrm{HA}$ - using $0.075 \mathrm{M} \mathrm{CaHPO}_{4}$ concentration for 25 hours hydrothermal time with 100 ppm surfactant exhibited antiviral effect $(52.9 \%)$ against Virus HSV1. HAV was slightly inhibited, whereas no antiviral activity was observed with respect to Adenovirus-5, and MERS.

\section{References}

[1] K. Ioku, S. Yamauchi, H. Fujimori, S. Goto, and M. Yoshimura, Hydrothermal Preparation of Fibrous Apatite and Apatite Sheet, Solid State Ionics 151 (2002), 147-150.

[2] F. Branda, A. Costantini, G. Luciani, F. Rosso, G. Peluso, and A. Barbarisi, Hydroxyapatite Coating of Polyelectrolite Hydrogels by Means of the Biomimetic Method, Materials Science \& Engineering C 23(2003), 367-370.

[3] A. Afshar, M. Ghorbani, N. Ehsani, M.R. Saeri, and C.C. Sorrell, Some Important Factors in the Wet Precipitation Process of Hydroxyapatite, Materials \& Design, 24(2003), 197-202.

[4] M. Niimi, T. Masuda, K. Kaihatsu, N. Kato, S. Nakamura, T. Nakaya, F. Arai, Virus Purification and Enrichment by Hydroxyapatite Chromatography on a Chip, Sensors and Actuators B: Chemical 201 (2004), 185-190.
[5] E.A. Abdel-Aal, D Dietrich, S Steinhäuser, T Lampke, Strontium-substituted Hydroxyapatite Coatings on Titanium by Electrodeposition Technique, Journal for Electrochemistry and Plating Technology 3 (2011), 29-40.

[6] R. Ramachandra Rao, H.N. Roopa, T.S. Kannan, Solid State synthesis and thermal stability of HAp and Hap- $\beta$-TCP composite ceramic powders, Journal of Materials Science-Materials in Medicine 8 (1997), 511-518.

[7] P. Wang, C. Li, H. Gong, X. Jiang, H. Wang, K. Li; Effects of Synthesis Conditions on the Morphology of Hydroxyapatite Nanoparticles Produced by Wet Chemical Process, Powder Technology 203, 2 (2010), 315-321, DOI:10.1016/j.powtec.2010.05.023

[8] E.A. Abdel-Aal, D. El-Sayed, M. Shoeib, A.T. Kandil, Enhancing Coating of Brushite/hydroxyapatite Layer on Titanium Alloy Implant Surface with Additives, Applied Surface Science, Part B, 285 (2013), 136-143.

[9] E.I. Dorozhkina, S.V. Dorozhkin, Application of the Turbidity Measurements to Study In Situ Crystallization of Calcium Phosphates, Colloids and Surfaces 203 (2002), 237-244.

[10] G. Bezzi, G. Celotti, E. Landi, T.M.G. La Torretta, I. Sopyan, A. Tampieri, A novel Sol-gel Technique for Hydroxyapatite Preparation, 
Materials Chemistry and Physics 78 (2003), 816824.

[11] W. Weng, G. Han, P. Du, G. Shen, The effect of Citric Acid Addition on the Formation of Sol-gel Derived Hydroxyapatite, Materials Chemistry and Physics 74 (2002), 92-97.

[12] K. Yamashita, T. Arashi, K. Kitagaki, S. Yamada, T. Umegaki, Preparation of Apatite Thin Films Through Sputtering From Calcium Phosphate Glasses, Journal of American Ceramic Society 77, 9 (1994), p. 2401-2407.

[13] C.C. Silva, A.G. Pinheiro, M.A.R. Miranda, J.C. Go' es, A.S.B. Sombra, Structural Properties of Hydroxyapatite Obtained by Mechanosynthesis, Solid State Sciences 5 (2003), 553-558.

[14] S. Nakamura, T. Isobe, M. Senna, Hydroxyapatite Nano Sol Prepared via a Mechanochemical Route, Journal of Nanoparticle Research 3 (2001), $57-$ 61.

[15] E.A. Abdel-Aal, A.A. El-Midany, and H. El-Shall, Mechanochemical-Hydrothermal Preparation of Nano-crystallite Hydroxyapatite Using Statistical Design, Materials Chemistry and Physics 112 (2008), 202-207.

[16] J. Liu, X. Ye, H. Wang, M. Zhu, B. Wang, and H. Yan, The Influence of $\mathrm{pH}$ and Temperature on the Morphology of Hydroxyapatite Synthesized by Hydrothermal Method, Ceramics International, 29, 6 (2003), 629-633.

[17] G.K. Lim, J.Wang, S.C. Ng, C.H. Chew, L.M. Gan, Processing of Hydroxyapatite via icroemulsion and Emulsion Routes, Biomaterials, 18 (1997). 1433-1439.

[18] X. Xiao, R. Liu, F. Liu, X. Zheng, D. Zhu; Effect of Poly(sodium 4-styrene-sulfonate) on the Crystal Growth of Hydroxyapatite Prepared by Hydrothermal Method, Materials Chemistry and Physics, 120 (2010), 603-607.

[19] H. Zhang, B. W. Darvell; Synthesis and Characterization of Hydroxyapatite Whiskers by Hydrothermal Homogeneous Precipitation using Acetamide, Acta Biomaterialia, 6 (2010), 32163222.

[20] H. El-Shall, M.M. Rashad, and E.A. Abdel-Aal, Effect of Phosphonate Additive on Crystallization of Gypsum in Phosphoric and Sulfuric Acid Medium, Crystal Research and Technology, 37 (2002), 1264-1273.

[21] M.M. Rashad, M.H.H. Mahmoud, I.A. Ibrahim and E. A. Abdel-Aal, Effect of Citric Acid and 1,2Dihydroxybenzene 3,5-disulfonic Acid on Crystallization of Calcium Sulfate Dihydrate Under Simulated Conditions of Phosphoric Acid
Production, Crystal Research and Technology 40, 8 (2005), 741-747.

[22] E. A. Abdel-Aal, H. M. Abdel-Ghafar, and M. B. El Anadouli; New Findings about Nucleation and Crystal Growth of Reverse Osmosis Desalination Scales with and without Inhibitor, Crystal Growth \& Design 15, 10 (2015), 5133-5137.

[23] H. El-Shall, M. M. Rashad, and E. A. Abdel-Aal; Effect of Cetyl Pyridinium Additive on Crystallization of Gypsum in Phosphoric and Sulfuric Acids Medium, Crystal Research and Technology 40, 9 (2005), 860-866.

[24] H. El-Shall, E. A. Abdel-Aal and B. Moudgil, Cost-Effective Reagents as Defoamers and Crystal Modifiers to Enhance the Filtration of Phosphogypsum, Publication No. 01-141-162, Florida Industrial and Phosphate Research Institute (FIPR) Project No. 96-01-141, Florida University, USA, (1999),1-63, https://fipr.floridapoly.edu/

[25] H. El-Shall, E. A. Abdel-Aal and B. Moudgil, Effect of Surfactants on Phosphogypsum Crystallization and Filtration during Wet-Process Phosphoric Acid Production, Separation Science and Technology Journal, 35, 3 (2000), 395-410.

[26] E.A. Abdel-Aal, M.H.H. Mahmoud, H. El-Shall, A.K. Ismail, Increasing the filtration rate of phospho-gypsum using surfactant, Hydrometallurgy, 85 (2007), 53-58.

[27] L. Yan, Y. Li, Z. X. Deng, J. Zhuang, and X. Sun, Surfactant-Assisted Hydrothermal Synthesis of Hydroxyapatite Nanorods, International Journal of Inorganic Materials, 3 (2001), 633-637.

[28] P. Vijayan, C. Raghu, G. Ashok, S.A. Dhanaraj, B. Suresh, Antiviral Activity of Medicinal Plants of Nilgiris, Indian J. Med. Res., 120 (2004), 24-29.

[29] W. Randazzo, J. Piqueras, J. Rodriguez-Diaz, R. Aznar and G. Sanchez, Improving Efficiency of Viability-qPCR for Selective Detection of Infectious HAV in Food and Water Samples, Journal of Applied Microbiology (2017), DOI 10.1111/jam.13519.

[30] R.M. Pinto, J.M. Diez, and A. Bosch, Use of the Colonic Carcinoma Cell Line $\mathrm{CaCo}^{-2}$ for In Vivo Amplification and Detection of Enteric Viruses. $J$ Med Virol 44 (1994), 310-315.

[31] T. Mosman, Rapid Colorimetric Assay for Cellular Growth and Survival: Application to Proliferation and Cytotoxicity Assays. $J$. Immunol. Methods, 65 (1983), 55-63.

[32] F. G. Hayden, K. M. Cote, R. G. Douglas Jr., Plaque Inhibition Assay for Drug Susceptibility 
Testing of Influenza Viruses, Antimicrobial Agents and Chemotherapy, 17, 6 (1980), 865-870, https//aac.asm.org

[33] T.N. Kaul, E. Jr Middleton, and P.L. Ogra, Antiviral Effect of Flavonoids on Human Viruses. J. Med. Virol., 15 (1985), 71-79,

[34] Hongquan Zhang, Youfa Wang, Yuhua Yan, and Shipu Li; Precipitation of Biocompatible Hydroxyapatite Whiskers from Moderately Acid Solution, Ceramics International, 29 (2003), 413-418.

[35] E.A. Abdel-Aal, D. Dietrich, S. Steinhaeuser, B. Wielage; Electrocrystallization of Calcium Phosphate Coatings on Titanium Substrate at Different Current Densities, Surface \& Coating Technology, 202 (2008), 5895-5900.

[36] E.A. Abdel-Aal; Inserting of Strontium during Coating of Hydroxyapatite Compound on Titanium Substrate, International Journal of Nanoparticles, No. 1, 4 (2011), 77-92.

[37] E.A. Abdel-Aal; Electrodeposition of Calcium Phosphate Coatings on Titanium Alloy Implant at Different $\mathrm{Ca} / \mathrm{P}$ Ratios and Different Times, International Journal of Nano and Biomaterials, No. 2, 3 (2010), 187-202.

[38] Q. Luo, J.D. Andrade, Cooperative Adsorption of Proteins onto Hydroxyapatite, Journal of Colloid and Interface Science, 200, 1(1998), 104113. 